\title{
Durability performance of concrete made with fine recycled concrete aggregates
}

\author{
L. Evangelista ${ }^{\mathrm{a}}$, J. de Brito $^{\mathrm{b}, *}$ \\ a Instituto Superior de Engenharia de Lisboa, R. Conselheiro Emídio Navarro, 1, 1950-062 Lisboa, Portugal \\ b Instituto Superior Técnico, Av. Rovisco Pais, 1049-001 Lisboa, Portugal
}

\section{A R T I C L E I N F O}

\section{Article history:}

Received 22 June 2009

Received in revised form 22 September 2009

Accepted 28 September 2009

Available online 4 October 2009

\section{Keywords:}

Concrete

Durability

Recycling

Fine aggregates

Water absorption

Chloride resistance

Carbonation resistance

\begin{abstract}
A B S T R A C T
Fine recycled aggregates are seen as the last choice in recycling for concrete production. Many references quote their detrimental influence on the most important characteristics of concrete: compressive and tensile strength; modulus of elasticity; water absorption; shrinkage; carbonation and chloride penetration. These two last characteristics are fundamental in terms of the long-term durability of reinforced or prestressed concrete. In the experimental research carried out at IST, part of which has already been published, different concrete mixes (with increasing rates of substitution of fine natural aggregates sand - with fine recycled aggregates from crushed concrete) were prepared and tested. The results were then compared with those for a reference concrete with exactly the same composition and grading curve, but with no recycled aggregates. This paper presents the main results of this research for water absorption by immersion and capillarity, chloride penetration (by means of the chloride migration coefficient), and carbonation resistance, drawing some conclusions on the feasibility of using this type of aggregate in structural concrete, while taking into account any ensuing obvious positive environmental impact.
\end{abstract}

(C) 2009 Elsevier Ltd. All rights reserved.

\section{Introduction}

It is now well established that the evaluation of the performance of a concrete mix is not limited to the determination of its mechanical properties since it is of paramount importance to characterize the material in terms of the parameters that rate its durability. The service life of a reinforced or prestressed concrete structure and its performance over time are closely connected with the properties that define durability, which include permeability (to various agents), alkali-silica reactivity, reaction to icing-deicing cycles, reaction to sulfates, and others [1].

Concrete made with recycled aggregates is no longer merely a research field; it is already a practical reality and has been used for some years in several countries which lead the way in these matters [2]. Various pilot projects have been implemented in these countries with encouraging results [3,4]. Its use is so widespread there that several of them have developed or are developing normative documents to regulate the use of this type of concrete in order to address its specificities [5].

In most codes the use of fine recycled aggregates in concrete production is restricted or even prohibited because of their unsatisfactory properties [6,7]. There are some studies, however, that suggest their use is not necessarily inauspicious and that good

\footnotetext{
* Corresponding author. Tel.: +351 218419709; fax: +351 218497650 .

E-mail address: jb@civil.ist.utl.pt (J. de Brito).
}

results (similar to those obtained with fine natural aggregates) are feasible in concrete which contain a proportion of this type of aggregate $[8,9]$.

IST (Lisbon, Portugal) has been conducting experimental research to assess the practicality of using fine recycled concrete aggregates to produce new concrete. The experimental program is studying various properties of concretes with different replacement ratios of fine natural aggregates by recycled ones. The results have been compared with those of a reference concrete of identical composition but produced with natural aggregates only. This paper presents the results for water absorption by immersion and through capillarity, the penetration of chlorides, measured in terms of the migration coefficient in a non-steady state, and carbonation resistance.

\subsection{Durability parameters}

The durability of a concrete element is greatly dependent on the capacity of a fluid to penetrate the concrete's microstructure allowing the introduction of molecules (e.g. carbon dioxide, chloride ions) that react and destroy its chemical stability. This movement is known to occur in three ways: permeation, capillarity and diffusion [10]. The durability of concrete made with fine recycled concrete aggregates (FRA) was analyzed by means of three tests, namely water absorption by immersion, water absorption through capillarity, and chloride penetration in a non-steady state condition. 
Water absorption by immersion measures the permeation capacity of concrete under a given pressure, i.e. the capacity of a fluid to move through the pore structure. This phenomenon depends mostly on the concrete microstructure (especially on the open pore structure), moisture condition and properties of the permeating fluid [11]. Although water absorption by immersion gives an estimate of the volume of a concrete's open pores, it is not a reliable way of determining the concrete's chloride and carbonation resistance, since this depends more on capillary absorption [12].

Water absorption through capillarity is a phenomenon that is due to the difference between the fluid's surface capillary pressure and its gravity pressure, which induces fluid movement until a balance is established. Capillary pressure increases with decreasing capillary diameter and is most relevant at the boundaries of concrete elements. The process is particularly visible in dry-wet conditions and has the most relevance near the element's surface.

The presence of chloride ions in concrete microstructure is known to lead to steel corrosion [13]. Carbonation is a chemical phenomenon where the carbon dioxide that penetrates the concrete structure reacts with calcium hydroxide to drastically reduce concrete alkalinity, enabling steel corrosion by destroying the passive layer. Carbonation depends on the cement's composition, aggregate type and porosity [14]. Together these two phenomena are the main factors in reducing concrete durability [10]. Both chloride penetration and carbonation tend to occur by diffusion, which is the movement of an element due to its concentration gradient within the concrete microstructure. This phenomenon is characterized by Fick's second law:

$\frac{\partial \phi}{\partial t}=D \frac{\partial^{2} \phi}{\partial x^{2}}$

where $\varphi$ is the ionic concentration, $t$ is the time, $D$ is the diffusion coefficient and $x$ is the position.

\section{Experimental program}

\subsection{Fine recycled concrete aggregate production}

The fine recycled aggregates used in the experimental research reported here were obtained by crushing the original concrete (OC) produced in the laboratory for that purpose in an impact crusher. By choosing this concrete as a source of recycled aggregates two problems were solved: first, it was guaranteed that all the aggregates used came from the same source, thus reducing the scatter that they often exhibit; second, it was possible to determine the main properties of the original concrete thereby permitting a better interpretation of the results. Table 1 gives the composition of the original concrete and some of its properties.

After 35 days, the concrete was crushed. The resulting material was composed of aggregates whose size ranged from 0 to $38.1 \mathrm{~mm}$. Of these sizes only the fractions up to $1.19 \mathrm{~mm}$ were used, since this was the maximum dimension of the fine natural aggregates

Table 1

Original concrete composition.

\begin{tabular}{ll}
\hline Materials & OC \\
\hline CEM II $32.5 \mathrm{~N}\left(\mathrm{~kg} / \mathrm{m}^{3}\right)$ & 362 \\
River sand $\left(\mathrm{kg} / \mathrm{m}^{3}\right)$ & 615 \\
Coarse aggregate $1\left(\mathrm{~kg} / \mathrm{m}^{3}\right)$ & 717 \\
Coarse aggregate $2\left(\mathrm{~kg} / \mathrm{m}^{3}\right)$ & 478 \\
Water $\left(\mathrm{l} / \mathrm{m}^{3}\right)$ & 188 \\
W/C & 0.52 \\
Slump $(\mathrm{mm})$ & $70 \pm 10$ \\
$f_{c m}: 7$ days $(\mathrm{MPa})$ & 21.0 \\
$f_{c m}: 28$ days $(\mathrm{MPa})$ & 29.6 \\
\hline
\end{tabular}

(river sand). After this screening, there were significant differences between the natural and recycled aggregates in terms of their grading curves. The recycled aggregates grading curve therefore had to be converted in order to reproduce that of the natural aggregates (so as to obtain the same fineness modulus for all the mixes with different replacement ratios and eliminate the influence of this parameter on the results). For this, all the recycled aggregates were sieved to obtain the various grading sizes and the different fractions were kept in sealed containers to prevent humidity exchange with the outside environment. Even though the practicability of this procedure leaves much to be desired, it was decided to go ahead with it since it would eliminate unwelcome entropies that would otherwise most surely hinder the analysis of the results obtained.

\subsection{Concrete mix design}

The calculation of the composition of the various mixes required the characterization of the aggregates used in them, with special emphasis on the properties of the fine aggregates. Table 2 presents the main properties of the fine recycled aggregates (FRA) and compares them with the fine natural aggregates (FNA). In brief, the recycled aggregates have lower specific densities than the natural aggregates because of their higher porosity, resulting in the greater water absorption observed.

The different compositions of concrete in terms of the FNA/FRA replacement ratio (30\% and 100\%) and the reference concrete (RC) produced with natural aggregates alone were studied in accordance with the methodology proposed by Faury [15], with workability (slump as measured by the Abrams cone) as a common characteristic, within the interval $80 \pm 10 \mathrm{~mm}$.

The first mixes were made with the $\mathrm{RC}$, thus determining the composition of the remaining concretes. The $\mathrm{W} / \mathrm{C}$ ratio (and consequently to calibrate the quantities of the remaining materials) had to be corrected for the subsequent mixes since the more angular shape of the particles of fine recycled aggregates produces higher inner friction [16].

Furthermore, it was necessary to introduce the water that the recycled aggregates were going to absorb during the mixing, to prevent it from being removed in the hydration process which would jeopardize the concretes' performance. Two different $\mathrm{W} / \mathrm{C}$ ratios therefore needed to be determined: the global $\mathrm{W} / \mathrm{C}$ ratio, i.e. the ratio between the overall quantity of water introduced into the mix and the amount of binder that, even though very simple to determine, is of no particular interest to the study of the concrete mixes, and the effective $\mathrm{W} / \mathrm{C}$ ratio, i.e. the ratio between the amount of free water within the mix and the amount of binder whose determination, though fundamental to understanding the concrete's performance, is difficult because the evolution of the water absorption by the recycled aggregates versus time has to be known in detail. This particular feature of recycled aggregates is of fundamental importance to the composition and performance of concretes made with them. In a research program at IST and UPC (Barcelona, Spain) under the joint supervision of the second author, the effect of the method of compensating for the coarse recycled concrete aggregates excessive water absorption in concrete

Table 2

Fine recycled and fine natural aggregates' properties.

\begin{tabular}{lll}
\hline Properties & FRA & FNA \\
\hline Dry specific density $\left(\mathrm{kg} / \mathrm{m}^{3}\right)$ & 1913 & 2544 \\
Surface dry specific density $\left(\mathrm{kg} / \mathrm{m}^{3}\right)$ & 2165 & 2564 \\
Dry bulk density $\left(\mathrm{kg} / \mathrm{m}^{3}\right)$ & 1234 & 1517 \\
Water absorption $(\%)$ & 13.1 & 0.8 \\
Fineness modulus & 2.38 & 2.38 \\
\hline
\end{tabular}


composition and mixing has been studied. The results have been included in a paper presently submitted for publication and clearly show that the method of water compensation during mixing, in order to achieve a given effective $\mathrm{W} / \mathrm{C}$ ratio, leads to better performance results for concretes made with these aggregates, when compared to those mixed using the traditional method (pre-saturating the aggregates).

The evolution of the amount of water absorbed by the recycled aggregates over time was determined using the method proposed by Leite [17]. The author devised a test which led to the conclusion that the amount of water absorbed by the fine recycled aggregates grew during the initial 10 min of immersion, more or less stabilized until the 30 min mark at around 50\% of the maximum absorption capacity of the aggregates, and grew again thereafter until saturation was achieved.

The author also quotes Neville [18] in the observation that the introduction of cement into the mix blocks the pores of the aggregates, thus dramatically reducing absorption and even halting it. Because of all this and since the pre-saturation process of the aggregates was going to last between 10 and 20 min before adding the binder, it was considered necessary to add an amount of water corresponding to $50 \%$ of the maximum water absorption capacity of the aggregates (Table 2:13.1\%), minus the water content already contained by the aggregates (4.3\%) in environmental conditions.

The composition of the different concrete mixes under analysis is presented in Table 3. Three coarse natural aggregates (CA) were used, all of them crushed from limestone. The cement used was CEM I 42.5R with a content of $380 \mathrm{~kg} / \mathrm{m}^{3}$ and this was kept constant in all the mixes. A superplasticizer made of modified carboxylates was also used. The content was $1.3 \%$ by weight of cement, which was also kept constant in the other mixes.

The mechanical properties of the concrete mixes were also tested with very good results [8]. Compressive strength presented little to no variation, even for concrete with $100 \%$ replacement ratio, while the maximum reduction of the modulus of elasticity was $18.5 \%$. The maximum reduction of tensile strength and abrasion resistance was about $30 \%$. Table 4 presents a summary of the obtained results.

\subsection{Specimen preparation and testing procedures}

Water absorption by immersion was tested using procedures established by the Portuguese National Laboratory of Civil Engi-

Table 3

Mixture composition $\left(/ \mathrm{m}^{3}\right)$.

\begin{tabular}{llll}
\hline & $R C$ & C30R & C100R \\
\hline \% of replacement & 0 & 30 & 100 \\
CEM I 42.5R (kg) & & 380 & \\
Water (1) & 155.8 & 170.2 & 180.9 \\
W/C & 0.41 & 0.45 & 0.48 \\
(W/C) ef & 0.41 & 0.44 & 0.45 \\
FNA (kg) & 668 & 460 & 0 \\
FRA (kg) & 0 & 154 & 509 \\
CA 1 (kg) & 409 & 402 & 400 \\
CA 2 (kg) & 382 & 376 & 374 \\
CA 3 (kg) & 397 & 390 & 388 \\
Superplasticizer (kg) & & 4.9 & \\
\hline
\end{tabular}

Table 4

Mechanical behavior of tested compositions.

\begin{tabular}{llll}
\hline & $R C$ & C30R & C100R \\
\hline Compressive strength (MPa) & 59.3 & 57.3 & 54.8 \\
Modulus of elasticity (GPa) & 35.5 & 34.2 & 28.9 \\
Splitting tensile strength (MPa) & 3.85 & 3.65 & 2.95 \\
Abrasion resistance (mm) & 1.96 & 1.86 & 1.37 \\
\hline
\end{tabular}

neering (LNEC) standard E394 [19]; 0.10 m edge cubic specimens were used. Four test specimens of each composition were kept submerged at $20 \pm 3{ }^{\circ} \mathrm{C}$ until constant mass was confirmed $\left(M_{s}\right)$. The specimens were then oven dried at $105 \pm 5{ }^{\circ} \mathrm{C}$ until constant mass was achieved $\left(M_{w d}\right)$. Water absorption by immersion measures the ratio of water absorbed during the process, by means of:

$W \%=\frac{M_{s}-M_{w d}}{M_{w d}}$

Water absorption through capillarity was determined on prismatic specimens with $0.10 \times 0.10 \mathrm{~m}^{2}$ base and $0.20 \mathrm{~m}$ height according to Portuguese standard E393 [20]. The specimens were placed on a tray in contact with water $5 \pm 1 \mathrm{~mm}$ deep, and the apparatus was kept at constant humidity of $60 \%$ and temperature of $20^{\circ} \mathrm{C}$. Test readings were taken on four test specimens after 3 , 6,24 , and $72 \mathrm{~h}$, following standard procedures, after which time the specimens were weighed to determine the amount of water absorbed.

The chloride penetration test was performed according to the Nordtest method [21], with a modified setup: the migration cell was assembled according to ASTM C1202 [22], as shown in Fig. 1. This test allows the accelerated establishment of resistance to chloride penetration in concrete by determining the non-steadystate migration coefficient of the chlorides, $D_{n s s m}$, according to Eq. (2.2). The results allowed the depth reached by the chloride penetration front at a pre-determined age to be extrapolated. Four cylindrical test specimens of $100 \mathrm{~mm}$ diameter and $50 \mathrm{~mm}$ height were tested for each composition.

$D_{n s s m}=\frac{R T}{z F E} \times \frac{x_{d}-\alpha \sqrt{x_{d}}}{t}$

where

$E=\frac{U-2}{L}$

$E$ is the electric field strength $(\mathrm{V} / \mathrm{m})$ and $U$ is the absolute value of applied voltage $(\mathrm{V})$.

$\alpha=2 \sqrt{\frac{R T}{z F E}} \times \operatorname{erf}^{-1}\left(1-\frac{2 c_{d}}{c_{0}}\right)$

$D_{n s s m}$ is the non-steady-state migration coefficient $\left(\mathrm{m}^{2} / \mathrm{s}\right), R$ the gas constant, $\left(R=8.314 \mathrm{~J} /\left(\mathrm{K} \mathrm{mol}^{-1}\right)\right), z$ the absolute value of ion valence, for chloride $(z=1), F$ the Faraday's constant $(F=9.648 \times 104 \mathrm{~J} /$ $(\mathrm{V} \mathrm{mol})), T$ the average temperature in the anode between the beginning and the end of the test $(K), L$ the thickness of the specimen $(\mathrm{m}), x_{d}$ the average chloride penetration depth $(\mathrm{m})$, measured after splitting the specimen in half and applying a $0.1 \mathrm{M}$ silver

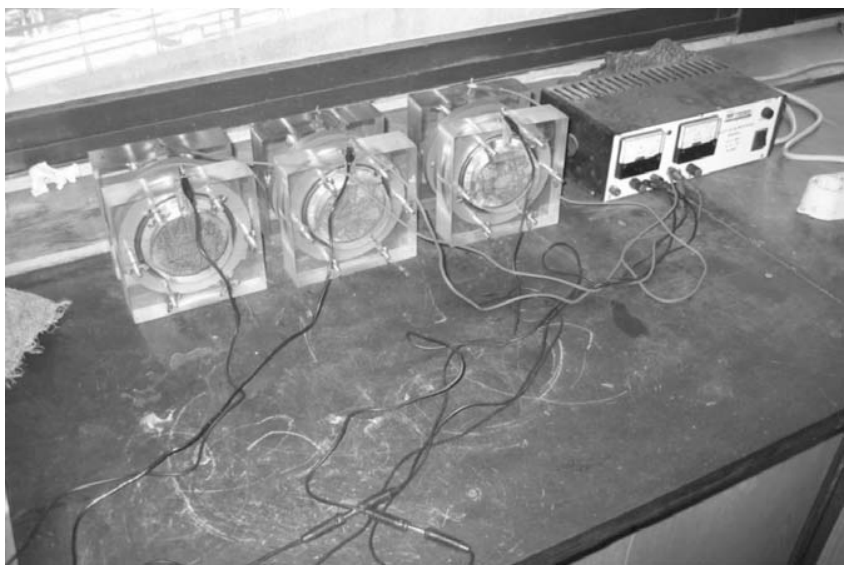

Fig. 1. Migration cells assembled for NT Build 492 test. 
nitrate solution, $t$ the test duration (s), $\operatorname{erf}^{-1}$ the inverse of error function, $c_{d}$ the chloride concentration at which the colour changes ( $c_{d} \approx 0.7 \mathrm{~N}$, for ordinary Portland cement) and $c_{0}$ is the chloride concentration in the cathode $\left(c_{0}=2 \mathrm{~N}\right)$.

The test specimens were cylinder-shaped, with a diameter of $100 \mathrm{~mm}$ and a height of $50 \mathrm{~mm}$, and were obtained by sawing taller cylinders of the same diameter. The cylindrical faces of the specimens were painted with epoxy based paint, in order to seal the migration cells.

Carbonation resistance was measured in an accelerated state, with specimens in a carbonation chamber with $5 \%$ concentration of $\mathrm{CO}_{2}$, following the recommendations of RILEM CPC-18 [23]. For each test age, specimens were split in half and immediately sprayed with a phenolphthalein solution, in order to measure the carbonation depth. Eight test specimens of each composition were tested.

\section{Results and discussion}

\subsection{Water absorption by immersion}

The average results achieved for water absorption by immersion are presented in Table 5. Concrete made with FRA alone saw water absorption by immersion increase by $46 \%$ while the increase in the composition where $30 \%$ of FNA was replaced by FRA was just $16.8 \%$.

For these results, a very good correlation $\left(R^{2} \approx 0.99\right)$ was achieved between water absorption and replacement ratio of FNA by FRA. The increase of water absorption by immersion was expected because FRA aggregates have a more porous structure which leads to an overall increase in the open pores in the concrete matrix [24].

\subsection{Water absorption through capillarity}

The average capillary water absorption is presented in Fig. 2, where $R C$ refers to the reference concrete and $C^{* *} R$ refers to concrete mixes with ${ }^{* *} \%$ replacement of FNA by FRA.

Wirquin et al. [25] suggests two models for determining capillary absorption in concrete mixes made with recycled aggregates. The first, introduced by Hall [26], suggests that capillary absorption is best modeled using Eq. (2.5):

$W=A+S \times \sqrt{t}-C . t$

where $W$ is the amount of water absorbed, $t$ the time, $S$ the material's sorptivity, and $A$ and $C$ are constants. The second model, based on Schönlin's work [27], suggests that capillary absorption should be modeled using Eq. (2.6):

$W=W_{1} \cdot t^{n}$

where $W$ and $t$ are defined as above, $W_{1}$ is the amount of water absorbed after $1 \mathrm{~h}$ and $n$ is a constant.

Using Hall's model, it was possible to define the capillary absorption for each mix tested and determine their sorptivities. The results are summarized in Table 6. Figs. 3-5 give the plots of

Table 5

Water absorption by immersion.

\begin{tabular}{lllll}
\hline & \multicolumn{2}{l}{ Water absorption } & & $\Delta(\%)$ \\
\cline { 2 - 4 } & $\mu(\%)$ & $\sigma(\%)$ & $C v$ & \\
\hline$R C$ & 11.3 & 0.11 & 0.0097 & - \\
C30R & 13.2 & 0.22 & 0.0167 & 16.8 \\
C100R & 16.5 & 0.32 & 0.0194 & 46 \\
\hline
\end{tabular}

$\mathrm{M}$ - mean; $\sigma$ - standard deviation; $C v$ - coefficient of variation.

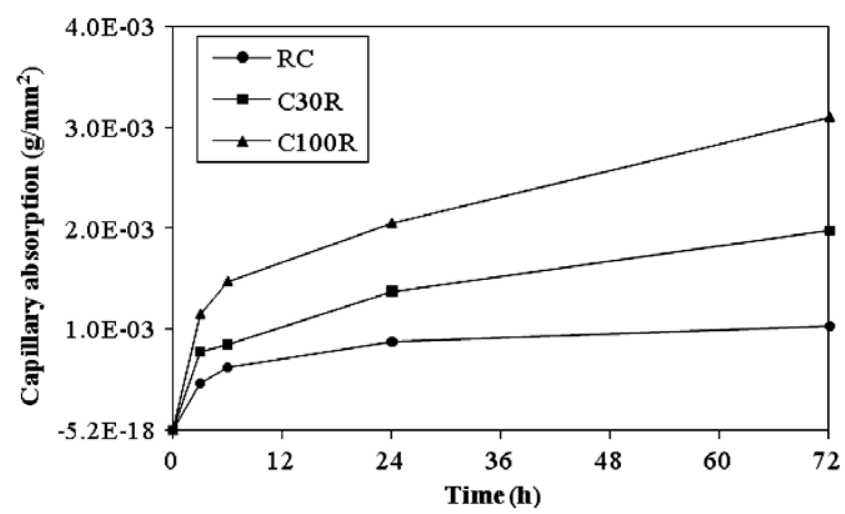

Fig. 2. Capillary water absorption.

Table 6

Correlation data for Hall's capillary model.

\begin{tabular}{llllll}
\hline & $A$ & $C$ & $S$ & $\Delta S(\%)$ & $R^{2}$ \\
\hline$R C$ & $2.3 \times 10^{-5}$ & $1.84 \times 10^{-5}$ & $2.73 \times 10^{-4}$ & - & 0.895 \\
C30R & $6.26 \times 10^{-5}$ & $1.70 \times 10^{-5}$ & $3.67 \times 10^{-4}$ & 34.4 & 0.972 \\
C100R & $3.19 \times 10^{-4}$ & $1.67 \times 10^{-5}$ & $4.65 \times 10^{-4}$ & 70.3 & 0.904 \\
\hline
\end{tabular}

the estimated functions along with surveyed data (each point refers to a test specimen), clearly showing the good correlation achieved. Sorptivity increased considerably (70.3\%) for concrete with complete replacement of FNA by FRA, while it shows an increase of $34.4 \%$ for concrete with a $30 \%$ replacement ratio. This variation seems to be linearly related to the amount of FRA included, as shown in Fig. 6. The amount of water absorbed increases because the presence of FRA creates more and longer capillaries [25] as a consequence of its own porosity, which increases capillary stress. Although the presence of FRA increases the sorptivity of concrete, some additional procedures could be used to reduce the negative effect, such as adding supplementary cementing

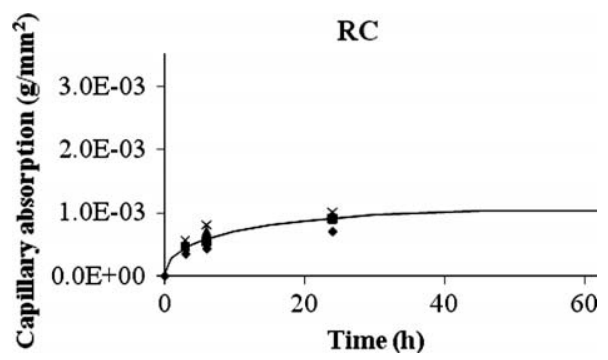

Fig. 3. Capillary absorption versus time for the reference concrete.

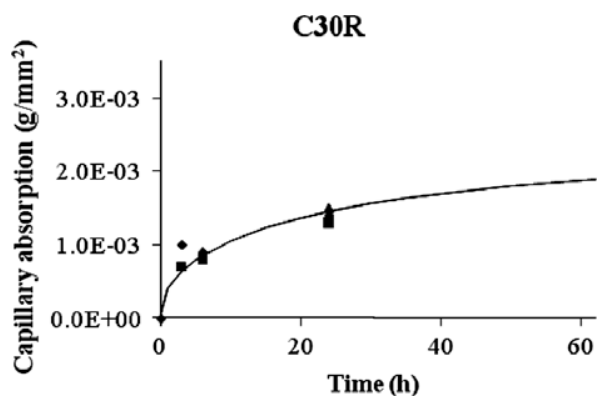

Fig. 4. Capillary absorption versus time for concrete C30R. 


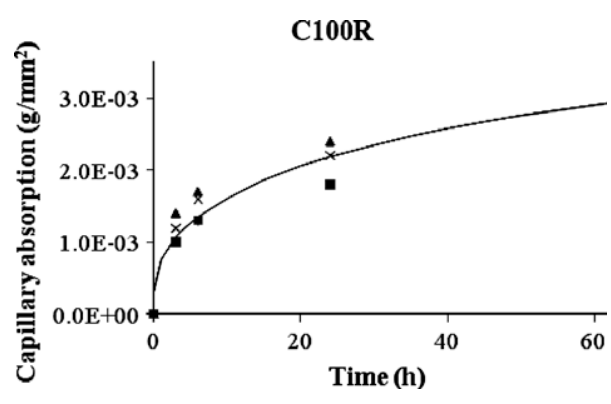

Fig. 5. Capillary absorption versus time for concrete C100R.

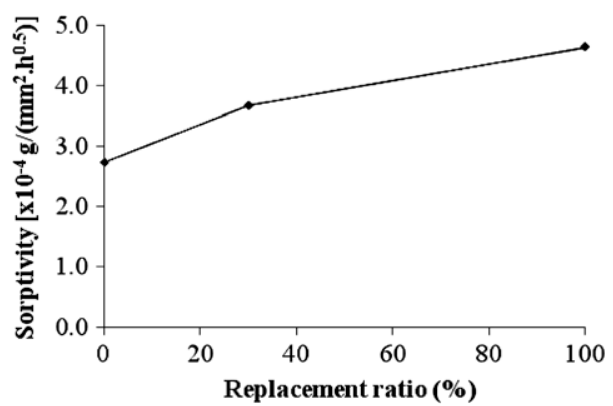

Fig. 6. Variation of sorptivity with FRA replacement ratio.

materials (SCM), such as silica fume, fly ash or blast furnace slag, as replacement for ordinary Portland cement (OPC), as these are known to improve sorptivity performance [28].

\subsection{Chloride penetration test}

The average results obtained for each concrete mix are presented in Table 7. An increase of around 12\% can be computed in terms of the migration coefficient when comparing the concrete with a 30\% FNA/FRA replacement ratio with the reference concrete, a difference that increases to $33.8 \%$ when the concrete with $100 \%$ replacement ratio is compared. Fig. 7 presents the mean values of the variation of chloride resistance with the replacement ratio of FNA by FRA, along with the standard deviation measured for each of the mix compositions.

The variation between the various migration coefficients is logical, since the process of penetration by the chloride ions is directly related to concrete porosity [29]. The latter grows linearly with the increase in the proportion of recycled aggregates (more porous than the natural ones), thus leading to a growing permeability. These values are considered good compared with those obtained by Limbachyia et al. [30] for high strength concrete made with coarse recycled concrete aggregates. Again, as with the sorptivity of concrete, the possible replacement of OPC with SCM could minimize the detrimental effect of the presence of FRA [28].

Table 7

Non-steady-state migration coefficient.

\begin{tabular}{lllll}
\hline & \multicolumn{2}{c}{$D_{\text {nssm }}\left(\mathrm{m}^{2} / \mathrm{s}\right)$} & & $\Delta(\%)$ \\
\cline { 2 - 4 } & $\mu(\%)$ & $\sigma(\%)$ & $C v$ & \\
\hline$R C$ & $17.99 \times 10^{-12}$ & $1.14 \times 10^{-12}$ & 0.0638 & - \\
C30R & $20.13 \times 10^{-12}$ & $2.11 \times 10^{-12}$ & 0.1049 & 11.9 \\
C100R & $24.07 \times 10^{-12}$ & $3.21 \times 10^{-12}$ & 0.1337 & 33.8 \\
\hline
\end{tabular}

$\mu$ - mean; $\sigma$ - standard deviation; $C v$ - coefficient of variation.

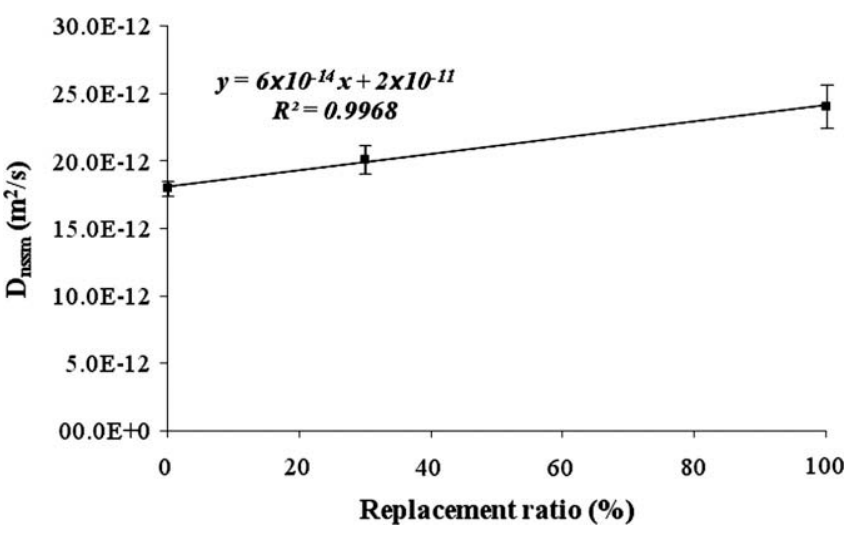

Fig. 7. Relationship between non-steady-state chloride migration coefficient variation and replacement ratio.

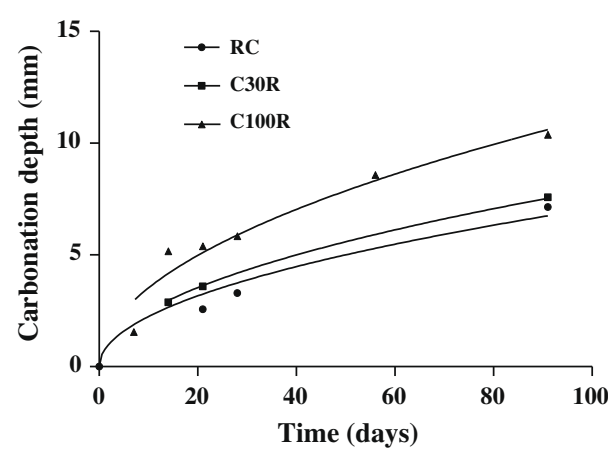

Fig. 8. Carbonation depth variation versus time.

Table 8

Correlation data for carbonation depth.

\begin{tabular}{lll}
\hline & $A$ & $R^{2}$ \\
\hline$R C$ & 0.708 & 0.81 \\
C30R & 0.790 & 0.83 \\
C100R & 1.110 & 0.77 \\
\hline
\end{tabular}

\subsection{Carbonation resistance}

Carbonation resistance was tested on cylindrical specimens of $150 \mathrm{~mm}$ diameter and $50 \mathrm{~mm}$ height whose circular faces had been sealed with an epoxy based paint so that $\mathrm{CO}_{2}$ could only penetrate through the side. A correlation was calculated for each set of data assuming a carbonation depth variation through time, as follows [31]:

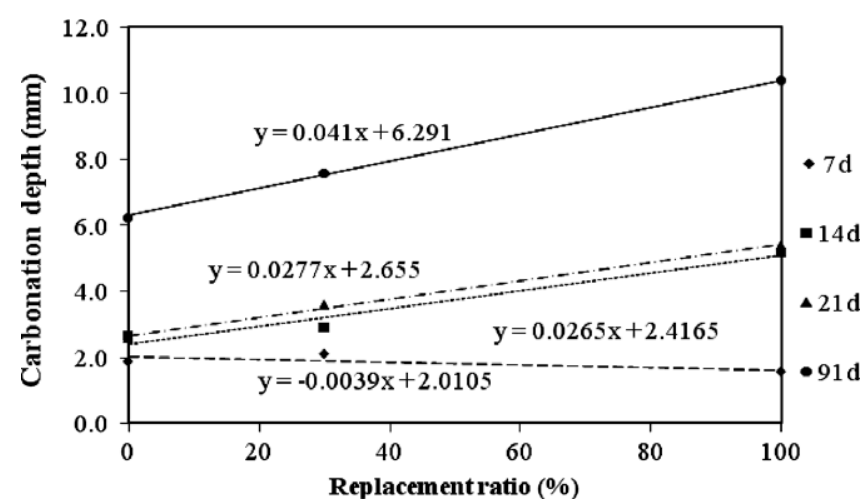

Fig. 9. Carbonation depth variation with FNA by FRA replacement ratio. 
$d=C_{d} \sqrt{t}$

where $d$ is the carbonation depth ( $\mathrm{mm}), C_{d}$ is the carbonation coefficient and $t$ is the time (days).

Average carbonation depth results and the best correlation fit for each composition are given in Fig. 8. Table 8 gives the correlation data for each of the analyzed curves. Carbonation depth increased with replacement ratio, which was to be expected since both capillary absorption and chloride penetration exhibited the same trend. Considering the variation of carbonation depth with the replacement ratio of FNA by FRA (Fig. 9), it is inferred that carbonation depth increases almost linearly with the replacement ratio, with a maximum increase of about $110 \%$ measured at 21 days for concrete made only with FRA, and a maximum increase of about $40 \%$, measured at the same age, for concrete with $30 \%$ replacement of FNA by FRA.

\section{Conclusions}

From the results obtained in the tests on concrete mixes where fine natural aggregates (FNA) were replaced by fine recycled concrete aggregates (FRA), the following conclusions can be drawn in relation to water permeability, capillary absorption and chloride diffusion:

- Water absorption by immersion increases with the replacement ratio of FNA by FRA, up to a maximum of $46 \%$ for concrete made solely with FRA, compared with a reference concrete using only FNA.

- FRA has a more detrimental effect on resistance to water absorption by capillarity than on water absorption by immersion; the sorptivity coefficient has a relative increase of $70.3 \%$ for concrete made with 100\% FRA compared with the reference concrete.

- In both cases, it seems that water absorption increases linearly with the replacement ratio; this is to be expected since FRA have a more porous structure, which extends to the concrete matrix.

- The non-steady-state chloride migration coefficient increases linearly with the replacement ratio of fine aggregates, reaching, in the present case, an increase of 34\% for the concrete with total replacement of FNA compared with the reference concrete with no FRA.

- Carbonation resistance is reduced with the addition of FRA to the concrete; the $\mathrm{CO}_{2}$ penetration depth increased about $40 \%$ for concrete made with $30 \%$ of FRA and around $110 \%$ for concrete made solely with FRA.

- For durability reasons the total replacement of the FNA by FRA in a concrete mix may present some serious difficulties; however, for smaller replacement ratios (e.g. 30\%), the use of FRA for structural concrete production is feasible, contrary to the widespread notion (even in codes) that they are inappropriate for this purpose.

- Considering that FRA have a non-negligible effect on concrete performance, it is feasible that the use of binders other than ordinary Portland cement (such as SCM) could compensate for the presence of FRA, maybe leading to higher acceptable replacement ratios.

- Furthermore, considering the acceptable mechanical behavior of these materials [8] and the fact that some structures are not affected by durability issues (e.g. concrete elements protected from natural aggressive agents), concrete FRA can be a useful source of material for concrete production and could potentially replace FNA in some concrete mixes.

\section{References}

[1] Basheer L, Kropp J, Cleland DJ. Assessment of the durability of concrete from its permeation properties: a review. Construct Build Mater 2001;15(2-3):93-103.

[2] Grübl P, Nealen A. Construction of an office building using concrete made from recycled demolition material. Darmstadt Concr 1998;13:163-77.

[3] Koulouris A, Limbachiya MC, Fried AN, Roberts JJ. Use of recycled aggregate in concrete application: case studies. Sustainable waste management and recycling: construction demolition waste. In: International Conference, Concrete and Masonry Research Group, Kingston University; September 1415 2004. p. 245-57.

[4] Poon C, Chan D. The use of recycled aggregate in concrete in Hong Kong. Res, Conserv Recycl 2007;50(3):293-305.

[5] Grübl P, Rhül M. German committee for reinforced concrete (DAfStb) - code: concrete with recycled aggregates. Sustainable construction: use of recycled concrete aggregate, University of Dundee, Concrete Technology Unit; November 11-12 1998. p. 8.

[6] Wainwright P, Trevorrow A, Yu Y, Wang Y. Modifying the performance of concrete made with coarse and fine recycled aggregates. In: Third international RILEM symposium on demolition and reuse of concrete and masonry; October 1994. p. 319-30.

[7] Zaharieva R, Buyle-Bodin F, Skoczylas F, Wirquin E. Assessment of the surface permeation properties of recycled aggregate concrete. Cement Concr Compos 2003;25(2):223-32.

[8] Evangelista L, de Brito J. Mechanical behaviour of concrete made with fine recycled concrete aggregates. Cement Concr Compos 2007;29(5):397-401.

[9] Khatib JM. Properties of concrete incorporating fine recycled aggregate. Cement Concr Res 2005;35(4):763-9.

[10] Mehta P, Monteiro P. Concrete: microstructure, properties and materials. 3rd ed. McGraw Hill; 2005.

[11] Olorunsogo FT, Padayachee N. Performance of recycled aggregate concrete monitored by durability indexes. Cement Concr Res 2002;32(2):179-85.

[12] de Schutter G, Audenaert K. Evaluation of water absorption of concrete as a measure for resistance against carbonation and chloride migration. Mater Struct 2004;37(9):591-6.

[13] Ann KY, Ahn JH, Ryou JS. The importance of chloride content at the concrete surface in assessing the time to corrosion of steel in concrete structures. Construct Build Mater 2009;23(1):239-45.

[14] Levy S, Helene P. Durability of recycled aggregates concrete: a safe way to sustainable development. Cement Concr Res 2004;34(11):1975-80.

[15] Faury J. Le Béton. 3rd ed. Paris: Dunod; 1958.

[16] 555 AC. ACI 555-01: removal and reuse of hardened concrete. American Concrete Institute; 2001.

[17] Leite M. Evaluation of the mechanical properties of concrete made with aggregates from construction and demolition waste, PhD Thesis. Porto Alegre, Brazil; 2001. (in Portuguese).

[18] Neville A. Properties of concrete. 4th ed. London: Longman; 1995.

[19] LNEC. Concrete: determination of the absorption of water by immersion. Lisbon: LNEC; 1993.

[20] LNEC. Concrete: determination of the absorption of water through capillarity. Lisbon: LNEC; 1993.

[21] Nordtest. NT Build 492: concrete mortar and cement based repair materials: chloride migration coefficient from non-steady-state migration experiments. Springer; 1999.

[22] ASTM. C1202-97: standard test method for electrical indication of concrete's ability to resist chloride ion penetration. ASTM; 1997.

[23] RILEM TC. CPC 18 measurement of hardened concrete carbonation depth. In: TC R. RILEM recommendations for the testing and use of constructions materials; 1988. p. $56-8$.

[24] Gómez-Soberón J. Porosity of recycled concrete with substitution of recycled concrete aggregate: an experimental study. Cement Concr Res 2002;32(8):1301-11.

[25] Wirquin E, Hadjieva-Zaharieva R, Buyle-Bodin F. Use of water absorption by concrete as a criterion of the durability of concrete - application to recycled aggregate concrete. Mater Struct 2000;33(6):403-8.

[26] Hall C. Water sorptivity of mortars and concretes. Mag Concr Res 1989;26(8):51-61.

[27] Balayssac JP. Relations entre performances mécaniques, microstructure et durabilité des bétons - PhD thesis held at INSA. Tolouse; 1992.

[28] Papadakis VG. Effect of supplementary cementing materials on concrete resistance against carbonation and chloride ingress. Cement Concr Res 2000;30(2):291-9.

[29] Gomes M, de Brito J. Structural concrete with incorporation of coarse recycled concrete and ceramic aggregates: durability performance. Mater Struct 2009;42(5):663-75.

[30] Limbachyia MC, Leelawat T, Dhir RK. Use of recycled concrete aggregate in high-strength concrete. Mater Struct 2000;33(9):574-80.

[31] Abbas A, Fathifazl G, Isgor OB, Razaqpur AG, Fournier B, Foo S. Durability of recycled aggregate next term concrete designed with equivalent mortar volume method. Cement Concr Compos 2009. 